\title{
Are we chronically sleep deprived?
}

\author{
W. B. WEBB and H. W. AGNEW, JR. \\ University of Florida, Gainesville, Florida 32601
}

\begin{abstract}
The sleep of 16 young adult male subjects was studied for 4 consecutive nights in the laboratory using all night electroencephalography. For the first 3 nights, the subjects retired for sleep at 11:00 p.m. and were aroused in the morning at 7:00 a.m. On the 4 th night, the subjects retired at 11:00 p.m. and were allowed to sleep in the morning until they awakened spontaneously. The ad-lib sleep night resulted in 126 min more sleep than was found on the 3rd night of controlled sleep. These results suggest the hypothesis that living in contemporary society produces a state of chronic sleep deprivation in humans.
\end{abstract}

Does life in the contemporary world make for a state of chronic sleep deprivation in humans? If we consider the nature of sleep in relation to the organization of the society we live in, it seems quite possible. In an oversimplification, we go to sleep when we wish to but we get up when we must. The advent of the electric light yielded fertile ground for extending our wishes well beyond the fall of darkness and the more recent television has added stimulation to that time.

For some years, bits and pieces of suggestive data have lent themselves to the idea of chronic sleep deprivation. In 1969, we noted that the sleep amount of 8- to 17-year-old students collected in 1910 and 1911 was $1 \frac{1}{2} \mathrm{~h}$ longer than a comparison group reporting in 1963 (Webb, 1969). In a 1937 study, using six-month sleep diaries, only one third of the subjects typically awakened spontaneously in the morning, and 50\% reported that they were not well rested upon awakening (Kleitman, Mullin, Cooperman, \& Titelbaum, 1937). More recently, in a questionnaire study of over 1,000 students, less than a third reported that they "typically wake up in the morning feeling fresh and rested;" one-third said that they "find it very hard to get up in the morning" (Agnew, Note 1).

A most provocative finding emerged from a recent study in which sleep logs were kept by 89 students for 2 weeks (White, Note 3 ). Their weekend sleep was an hour longer than their weekday sleep $(7.4 \mathrm{~h}$ vs. $8.3 \mathrm{~h})$. This is in accord with a similar finding by Johns, Gay, Goodyear, and Masterson (1971) using medical students. This difference may be enhanced in a more "job-bound" population.

More recently, laboratory data has yielded further suggestive evidence. Fourteen subjects were placed on an ad-lib sleep regime in a schedule-free environment which eliminated all cues as to time of day (Webb \& Agnew, 1974a). All exceeded their self-reported average of about $71 / 2 \mathrm{~h}$ of sleep each night. The average total sleep for 14 days was $120 \mathrm{~h}$ or an average of $8.6 \mathrm{~h}$ per day. In another study, four subjects were placed on a rigidly controlled sleep regime for 10 days in which the lights were turned out at 11:00 p.m., and they were aroused from sleep at 7:00 a.m. They averaged $7 \mathrm{~h}$ and $24 \mathrm{~min}$ of sleep per night. On the 11 th night, they were allowed to sleep as long as they wished. Under this condition, they averaged $8 \mathrm{~h}$ and $51 \mathrm{~min}$ per night for the next 10 days (Webb \& Agnew, 1974b).

In the present study, 16 male subjects with a mean age of 21.7 years were selected for study on the basis of their responses to the University of Florida sleep inventory. The principal criteria for selecting an individual for study was his self-report of good physical health, freedom from sleep disorders, freedom from the habitual use of drugs including alcohol, and a reported average sleep length of 7 to $8 \mathrm{~h}$.

The subjects slept in the laboratory for 3 consecutive nights between 11:00 p.m. and 7:00 a.m. On the 4th night of sleep in the laboratory, they retired at 11:00 p.m. but were allowed to sleep in the morning until their electroencephalograms (EEG) showed $10 \mathrm{~min}$ of continuous Stage 0 (wakefulness). The subjects were unaware that they would be allowed to sleep longer on the 4th night, and they slept in chambers which eliminated all cues as to time of day. On each night, the subjects reported to the laboratory $1 \mathrm{~h}$ prior to bedtime to be wired for the EEG and the electrooculogram (EOG). Recording procedures and procedures for scoring the all-night EEG-EOG records for stages of sleep have been given in detail by Agnew and Webb (1972). But, for the purposes of the present study, a 1 -min epoch of record was classified as Stage 0 if it contained at least $30 \mathrm{sec}$ of alpha $(8-12 \mathrm{~Hz})$ activity.

Table 1 compares the distribution of sleep time to the various stages of sleep on the $3 \mathrm{rd}$ night of sleep with sleep on the following ad-lib sleep night. When Stage 0 after sleep onset is excluded from consideration, these subjects averaged $454 \mathrm{~min}$ of sleep on the 3rd night and $580 \mathrm{~min}$ on the ad-lib sleep night. All subjects showed an increase on the ad-lib sleep night. These increases ranged from $31 \mathrm{~min}$ to $312 \mathrm{~min}$ and are significant at $\mathrm{p}<.02$, using a two-tailed $t$ test for related means. Forty-six percent of the increased sleep was given over to Stage 2, $36 \%$ was taken up by Stage REM, and $15 \%$ was spent in Stage 1 without REM.

Considering the empirical data, after a period of controlled sleep which permitted up to $8 \mathrm{~h}$ of sleep, 
Table 1

Comparison of the Distribution of Sleep to the Various Stages on Baseline Night 3 With the Following Night of Ad-Lib Sleep

\begin{tabular}{|c|c|c|c|c|c|c|c|}
\hline & \multicolumn{6}{|c|}{ Sleep Stage (Minutes) } & \multirow{2}{*}{$\begin{array}{l}\text { Sleep Length } \\
\text { (Excluding } \\
\text { Stage 0) }\end{array}$} \\
\hline & 0 & $' 1^{\prime}$ & REM & 2 & 3 & 4 & \\
\hline Third Baseline & 9 & 19 & 118 & 230 & 30 & 57 & 454 \\
\hline Ad-Lib Sleep & 19 & 38 & 164 & 289 & 29 & 60 & 580 \\
\hline Difference & +10 & +19 & +46 & +59 & -1 & +3 & +126 \\
\hline
\end{tabular}

ad-lib sleep showed a significant increase in amount. The increases in Stage REM and Stage 2 amounts are in accord with earlier findings relative to prolonged sleep and reflect the well-established facts that REM sleep is higher in amount in the later phases of the sleep period (Agnew \& Webb, 1973; Verdone, 1968) and Stage 2 is essentially linearly distributed across the night (Silverstein, Note 2). The lack of increase in Stage 4 amount is similarly in accord with earlier findings and reflects the previously established tendency for Stage 4 to occur primarily in the first third of the regular sleep period.

Back to our original question: are we chronically sleep deprived? Our laboratory data provides strong evidence that when sleep is freed from time limitations, it shows a sharp increase in amount and exceeds significantly the average of between 7 and $8 \mathrm{~h}$ that many individuals report again and again as their day-to-day sleep diet. The hypothesis that this increase in length is a response to a sleep debt fits a recently reported finding that when sleep is experimentally restricted in length on one night it responds by a subsequent extension of the amount of sleep (Agnew \& Webb, 1975).

Of course, our data does not consitute proof of chronic sleep deprivation in humans. Perhaps, as in the case of eating, given unlimited amounts of food, we will eat more than we need. Our regular sleep diets may be simply and sensibly keeping us from being "sleep fat."

\section{REFERENCE NOTES}

1. Agnew, H. W., Jr. From data collected at the University of Florida Sleep Laboratory, 1974.

2. Silverstein, L. D. Temporal and intrastage distribution of spindle activity during sleep. Unpublished Masters Thesis, University of Florida, 1974.

3. White, R. Personal communication, 1975.

\section{REFERENCES}

Agnew, H. W., Jr., \& Webb, W. B. Sleep stage scoring. Journal Abstract Supplement of the American Psychological Association, Ms. No. 293, May 1972.

Agnew, H. W., Jr., \& Webb, W. B. The influence of time course variables on REM sleep. Bulletin of the Psy chonomic Society, $1973,2,131-133$.

Johns, M., Gay, T., Goodyear, M., \& Masterson, J. Sleep habits of healthy young adults: Use of a sleep questionnaire. British Journal of Preventive and Social Medicine, 1971, 25, 236-241.

Kleitman, N., Mullin, F., Cooperman, N., \& Titelbaum, S. Sleep characteristics. Chicago: The University of Chicago Press, 1937.

Verdone, P. Sleep satiation: Extended sleep in normal subjects. Electroencephalography and Clinical Neurophysiology, 1968, $24,417-423$.

Webb, W. B. Twenty-four-hour sleep cycling. In: A. Kales (Ed.) Sleep: Physiology and pathology. Philadelphia: Lippincott, 1969. Pp. 53-65.

Webb, W. B., \& Agnew, H. W., Jr. Sleep and waking in a time free environment. Aerospace Medicine, 1974, June, 617622. (a)

Webb, W. B., \& Agnew, H. W., Jr. Regularity in the control of the free-running sleep-wakefulness rhythm. Aerospace Medicine, 1974, July, 701-704, (b)

Webb, W. B., \& Agnew, H. W., Jr. Effects on subsequent sleep of an acute restriction of sleep length. Psy chophysiology, 1975, in press.

(Received for publication April 24, 1975.) 